\title{
Epistemological progress in physics and its impact on biology
}

\author{
Julia Gouvea, ${ }^{1,2, *}$ Vashti Sawtelle, ${ }^{3,4}$ and Abhilash Nair ${ }^{4}$ \\ ${ }^{1}$ Department of Education, Tufts University, Medford, Massachusetts 02155, USA \\ ${ }^{2}$ Department of Biology, Tufts University, Medford, Massachusetts 02155, USA \\ ${ }^{3}$ Lyman Briggs College, Michigan State University, East Lansing, Michigan 48825, USA \\ ${ }^{4}$ Department of Physics and Astronomy, Michigan State University, East Lansing, Michigan 48825, USA
}

(Received 26 August 2018; published 22 January 2019)

\begin{abstract}
Epistemologically oriented reforms of physics courses aim to change the way students think about knowledge and approach learning in physics. A broader goal of these reforms is to impact how students think about knowledge and learning in other courses. We investigate the effects of epistemological reforms in a physics course on knowing and learning in biology courses through a case study of a biology major, Phillip, who was enrolled in a year-long reformed introductory physics for the life sciences (IPLS) course. First, we show that Phillip's epistemological framing of the physics course became more sophisticated, aligning with reforms designed to emphasize reasoning with foundational principles, seeking meaning and coherence. He also developed an approach to learning physics that involved coordinating understanding between course readings and class discussions and reconciling discrepancies with peers and the teaching assistant. Second, we present evidence of the impact of this new epistemological framing on Phillip's interpretation of his biology courses. Before the year in physics, Phillip framed his biology courses as about understanding. By the end of the year, Phillip reversed his stance on biology learning, reporting that he had actually been memorizing all this time. We discuss these results to highlight the success of epistemological reforms in physics beyond the confines of the physics classroom, to motivate attention epistemological reform beyond physics, and to offer suggestions for how IPLS courses can work towards creating epistemological connections to other disciplines.
\end{abstract}

DOI: 10.1103/PhysRevPhysEducRes.15.010107

\section{INTRODUCTION}

Epistemologically oriented reforms of physics courses aim to change how students think about knowledge and approach learning in physics [1-6]. For many reasons, students may enter physics classrooms with ideas about physics knowledge that can promote unproductive approaches to learning [7]. Most commonly, students may consider knowledge in physics to be comprised of abstract knowledge, often in the form of mathematical equations, disconnected from their everyday experiences [7-9]. With such a view of physics knowledge, learning strategies such as rote memorization can seem appropriate, and students are not bothered when answers do not make sense to them- they do not expect them to [10]. Epistemological reforms aim to help students see physics as a pursuit of coherent and sensible ideas about the world and learning physics as an active

\footnotetext{
*Corresponding author. julia.gouvea@tufts.edu

Published by the American Physical Society under the terms of the Creative Commons Attribution 4.0 International license. Further distribution of this work must maintain attribution to the author(s) and the published article's title, journal citation, and DOI.
}

process of building connections among those ideas. Equations should connect with physical intuitions and inconsistencies between physical principles and everyday experiences should be reconcilable.

Courses designed specifically to foster more sophisticated approaches to knowing and learning in physics have been successful in shifting students' responses to epistemological surveys. While traditional physics courses often produce negative shifts on epistemological surveys like the Colorado Learning Attitudes About Science Survey (CLASS) [11] and the Maryland Physics Expectations Survey (MPEX) [10,12], reformed approaches have been successful in supporting positive shifts. For example, Redish and Hammer [6] describe a reformed course in which they made epistemological principles like coherence seeking and sense making explicit and central to the course design and assessment structure. Redish and Hammer [6] found shifts on the MPEX-II survey in this reformed class. Other approaches to epistemological reform in physics have since demonstrated similar gains (see Ref. [13] for meta-analysis).

This work represents progress towards meeting a primary goal of these reforms - to shift how students think about knowledge and learning in physics. However, such reforms have broader goals too. The hope is that the effects of reformed courses will extend beyond physics to impact 
how students think about knowledge and learning in other courses, and possibly in their everyday lives. Redish and Hammer [6] hint at these broader goals with the story of "Louis," a student who experienced a shift in his approach to learning in his physics course and then went on to improve his overall GPA. Louis sent a note back to his physics instructor, writing, "I think this increase in GPA has a lot to do with the things I learned in your class-not about physics, but about learning in general." Hammer et al. [14] describe Louis as a possible case of epistemological "transfer," proposing that his experience in the physics course may have helped cohere and stabilize an orientation to learning focused on seeking meaning and understanding more generally.

While this anecdote is promising, very few studies have actually examined the effects of epistemological reforms beyond the confines of a single course. Such impacts are particularly important to understand given that the majority of students who take introductory physics courses are not physics majors. They are much more likely to be life science majors [15] who hope to learn physical principles and problem-solving approaches relevant to their majors and future careers $[16,17]$.

In the context that we report on here, an Introductory Physics for Life Sciences (IPLS) course, most of the students enrolled in the course had already declared a major in a life science field. While one goal of this course was to help these life science students learn physics content and develop "an appreciation for physics," another was to develop general scientific competencies, including productive epistemological orientations [18].

Our purpose in this article is to examine the question of how epistemological progress in a physics course can influence how students conceptualize and approach learning in other courses - in this case primarily biology. We do so by presenting a case study of a biology major, Phillip, who stood out to us as a student who was approaching learning in physics in line with the aims of the epistemological reforms - seeking coherence and meaning, listening and talking through inconsistencies with his peers and the instructor, and studying for understanding rather than attempting to memorize. Over the course of his year-long experience in the reformed physics course we saw evidence of Phillip's ideas about learning for understanding deepen and become more connected to concrete strategies for learning physics. From the perspective of this physics course, Phillip's progress was a desirable outcome.

Phillip also caught our attention as a student who expected connections across the disciplines and desired more overlap in his coursework. Specifically, at the beginning of the year he expected both biology and (more tentatively) physics to involve learning for understanding. We might have expected therefore that Phillip would be ideally positioned to apply some of the new ideas and approaches to deep learning that he was developing in his physics course to his biology courses.
Yet we did not see evidence of this. Instead, at the end of the year, Phillip reversed his stance towards knowledge and learning in biology from describing biology as about understanding how things work to memorizing all the details. Phillip also recharacterized his past experiences, reporting that he now saw that he "has been memorizing this whole time." This reversal explains why Phillip did not apply the deep learning strategies from physics to biology; he did not see them as relevant. We argue that Phillip's epistemological progress in physics changed how he interpreted the epistemic demands and values of his biology courses, and that this interpretative ability is a form of "epistemological transfer."

In the remainder of this paper we first describe how epistemological progress in one course could be expected to influence students' perceptions and behaviors in other courses using the theoretical framework of epistemological framing [14]. We highlight in particular the importance of framing that links contexts, or framing for intercontextuality $[19,20]$. We then present the case of Phillip, describing both his progress in physics and his shifting perspective on biology in terms of shifts in epistemological framing. We end by discussing the implications of this case study for epistemological reform across science courses including the need epistemological bridges across different disciplinary contexts.

\section{EPISTEMOLOGICAL FRAMING WITHIN AND ACROSS DISCIPLINARY CONTEXTS}

\section{A. Epistemological framing and approaches to learning}

The phenomenon of interest in this paper is how students approach learning in their science courses. Epistemological reforms target deep as opposed to surface approaches to learning - hoping to encourage students to meaning seeking rather than rote acquisition [21,22]. While there are many factors that can influence how students approach learning in a course, in this paper we focus on the role of how students conceptualize the nature of knowledge and knowing in those contexts through the process of epistemological framing ${ }^{1}[14,25,26]$.

Generally, framing refers to the continuous interpretation and adjustment that occurs as individuals make sense of how to behave in particular situations or settings [27,28]. Framing is influenced both by an individual's prior knowledge and experiences and by the physical and social cues presented by a setting. Epistemological framing describes a subcategory of framing that involves interpreting the knowledge forms and knowledge activities that are valued or appropriate $[8,14,25]$. For example, when students enter a lecture hall they might expect that the primary epistemic activity will involve receiving knowledge from an instructor.

\footnotetext{
${ }^{1}$ That is, we consider ideas about the nature of knowledge in disciplines and disciplinary courses, as well as approaches to learning that knowledge, as relevant to our understanding of Phillip. For a discussion of whether students' "epistemologies" should encompass approaches to learning or not see Refs. [23,24].
} 
One part of the explanation for this framing involves the prior knowledge and experience that students bring with them. Hammer and Elby [29] proposed that this prior knowledge is composed of epistemological resources ${ }^{2}$ abstract, fine-grained ideas about the nature of knowledge and the processes that generate it. Students in a lecture hall may have prior experiences with knowledge as something that can be transmitted from person to person for example.

A second critical component of the framing process involves the physical and social cues from the setting that influence which sets of resources individuals activate and for how long [30,31]. If the instructor begins to lecture, and other students begin to take notes, a framing of the activity in terms of knowledge transmission may be reinforced. However, the instructor could instead pose an open-ended question and attempt to engage the class in a discussion. The impact of this cue will play out in interaction with students' prior experiences. For some students the move by the instructor may activate a different subset of resourcesperhaps ideas related to knowledge construction and evaluation and their own ability to participate in such activity. Other students might expect, based on their prior experiences, that the instructor will soon provide the answer. They might not bother to meaningfully engage, expecting that the main activity in the lecture still revolves around the instructor transmitting knowledge to students. The lack of shift need not mean that these students do not have other resources for understanding and participating in that epistemic activity; additional support may be required for new framings to emerge.

The above example illustrates how epistemological framing emerges from the dynamic interaction between individuals and contexts. This dynamic can make it difficult to pinpoint epistemological sophistication. We might, for example, think of knowledge transmission as an unsophisticated way to frame a learning environment. Yet it would be inappropriate to attribute this lack of sophistication to students when years of experience in lecture classes have trained them to expect that this framing is appropriate [2]. In the next section we will build on this basic model of epistemological framing to describe progress towards epistemological sophistication within a context.

\section{B. Epistemological sophistication and progress within a context}

Elby and Hammer [32] have argued that particular epistemological resources or framings cannot themselves be evaluated as more or less sophisticated independent of context. For example, while it has been widely argued that the idea that "knowledge is tentative" is an expert-like conception of scientific knowledge, Elby and Hammer [32] have argued that the sophistication of this idea in science

\footnotetext{
${ }^{2}$ Any reference to "resources" in this paper is meant to refer to epistemological resources.
}

depends on when and how it is applied. While it may be appropriate for a student to treat knowledge from a single experimental trial as tentative, it might stifle progress for a student to refuse to make any starting assumptions because they are not $100 \%$ certain they are correct. Epistemological sophistication, argue Elby and Hammer [32], should therefore be understood in terms of what resources are likely to be "productive" within a context.

In the context of introductory physics, Hammer, Elby, and others have argued that framing physics knowledge as a collection of meaningless equations to memorize will not yield productive engagement in learning physics. Framings that emphasize coherence, seeking the physical meaning in symbols and reconciling everyday experiences with physical principles are considered more sophisticated in that they will support productive engagement in physics learning $[3,5-8,22,25,32]$. If initially these sophisticated framings are fleeting or rare, an increase in the frequency or duration of these framings can be considered progress $[14,30]$.

Earlier we introduced Louis, a student said to have made progress in learning physics. Hammer et al. [14] do not argue that Louis acquired an entirely new way of learning from his physics course. Instead, they argue that Louis already had resources about knowing and learning from his prior experiences. Louis' progress involved applying those resources to learning physics with increased frequency. We might also imagine progress entailing a growing coherence among productive resources and behaviors. What might begin as seeking to understand the meaning in equations could expand to include seeking the physical meaning in graphs and more generally checking to see how physics ideas make sense with one's experiences in the physical world. Overall epistemological progress could be defined as an increase in frequency of activation and coordination among productive resources, which should lead to more stable and sophisticated framings [14,30,33].

It makes sense then to consider the goal of epistemological reforms is to destabilize the activation of unproductive resources and promote the activation of productive resources that students already have- to "tap" into these resources and establish them as useful for learning in physics class [5,6]. It appears that with explicit and consistent messaging from instructors and with changes in activity and assessments, a course can be successful in supporting shifts in intended directions.

Notice however that this definition of progress depends on a consistent understanding of what counts as productive within a context. In a reformed physics course, it is consistently productive to make sense of equations, so an increase in this activity is a clear indicator of progress towards sophistication. However, as contexts shift what counts as sophistication might shift as well. YerdelenDamar and Elby [22] described how students in a reformed high school physics class were subjected to competing messages about what would be most productive for their 
learning. The reformed class taught them to approach learning physics as understanding and coherence building. At the same time, these students knew they would have to take a high stakes college entrance exam at the end of the year. The pressure from the test activated surface approaches to learning aimed and memorizing and quickly and efficiently solving problems. What can be said about the sophistication of this approach?

On the one hand, the rote strategies were unlikely to deepen students' understanding of physics and could therefore be considered unproductive for learning physics. On the other hand, signals from the high-stakes exam: a timed test, no opportunity to explain one's thinking, and a large amount of material to know, communicated that deep learning strategies were not valuable and might not guarantee a good score. Thus, it can be considered sensible and productive for students to compartmentalize-learning for understanding in the course and switching to a test-prep strategy for the exam. The approach is sensible because it correctly "reads" the epistemic values of each context, and memorizing may indeed help students with their score. This highlights a metacognitive dimension of sophisticated epistemological framings [34]. It can be considered sophisticated to actively interpret the epistemic values or demands of a context and adapt one's learning strategy accordingly.

Still, we could also imagine an approach that is more integrated. We might imagine an instructor doing some work to show students how understanding the meaning behind equations could also help with recall, or how memorizing certain mathematical relationships would allow them to spend more time reasoning through a problem. This kind of intentional relating of approaches to learning across contexts (course and exam) is an example of epistemological framing that could generate intercontextuality $[19,20]$. When the contexts are framed as distinct, the strategies compartmentalized, whereas intercontextual connections across the contexts could allow for more fluidity, potentially allowing deep-learning strategies to be applied to studying for the exam as well.

\section{Epistemological framing across contexts}

Our main interest in this paper is to explore how epistemological progress in one context might impact another. Louis's story represents one possible outcomethat progress in one context positively impacts how a student frames knowing and learning in another.

Hammer et al. [14] propose two types of mechanism that can facilitate this outcome. One mechanism is passive or context driven; features of context subconsciously elicit the activation of similar sets of resources. For example, another instructor or course structure could have communicated the value of explaining thinking clearly and simply. In this context Louis might have cued up the same set of resources that he had used earlier in his physics class. Having just activated this set made it easier to activate the same set again, even if unconsciously.

A second possibility involves active, conscious, application of resources across contexts. This application would require some degree of metacognitive awareness. That is, Louis may have become aware that a particular set of resources or strategies was relevant and useful. He then willfully applied those strategies in a new context. That Louis emailed his professor about his strategy use suggests that Louis was actively aware or at least became actively aware of the connection at some point.

Whether the activation is passive or active, a critical part of the mechanism is that there is some similarity or connection between the two contexts that supports a shared framing, what Engle refers to as intercontextuality $[19,20]$. If there is no such connection, neither passive nor active activation would be likely. Instead, we would expect individuals to activate a different set of resources, like the high school students did when they encountered a highstakes testing situation [22]. For Louis, we might imagine that the self-explanation framing would be generally reinforced across many of his classes. It is relatively easy to imagine that in his coursework generally, Louis would not encounter any strong cues telling him not to engage in this practice. Thus, while Hammer et al. [14] emphasize the impact of physics on Louis, the alignment among contexts was also part of what facilitated a broader activation of Louis' framing beyond physics.

In this paper we are specifically interested in epistemological connections across disciplinary contexts. In the next section we discuss prior work that suggests students may use disciplines as features of context that can cue up different or similar epistemological framings. Specifically, if disciplinary contexts present different or conflicting epistemological messages, those messages could impede the activation of similar framings.

\section{Discipline-specific epistemological framing}

Different disciplinary contexts seem to cue up different sets of epistemological resources for students. Hofer [35] showed that students responded differently to items on an epistemological survey when cued to think about either "psychology" or "science" when giving their answers. Thinking about science made it more likely for students to answer that knowledge was certain as opposed to tentative. Buehl and Alexander [36] found a similar pattern: students tended to associated certainty more strongly with mathematics than history. And Tsai [37] found a difference within science, with students reporting that knowledge was more certain when they had physics as opposed to biology in mind.

These studies provide evidence that students tend to associate different epistemological principles more strongly with certain disciplines, at least in the abstract. But how much do they matter for students in classrooms? A study by 
Lucas and Roth [38] suggests abstract ideas may not matter very much for how students approach their own learning. The authors taught a physics course with an explicit focus on the nature of knowledge in science-emphasizing, for example, the tentative nature of knowledge. While students did come to understand these abstract ideas, the intervention did not disrupt expectations of certainty in learning physics: It is possible to understand knowledge as tentative in scientific practice and still expect learning physics to involve acquiring established facts. Epistemological framing helps explain this. In the context of learning in a course, it is more likely that students will activate epistemological resources specifically tied to school learning because these are the resources that are most relevant in that context $[33,34]$.

Nevertheless, we do not want to completely rule out the possibility that epistemological resources about the disciplines could interact with instructional framings [39,40]. For instance, high-level ideas about the certainty of physics may reinforce, or be reinforced by, instructional framings of learning physics as knowing the correct answers. And high-level ideas about biology as a discipline that contains innumerable detailed facts could reinforce instructional framings around knowing and recalling as appropriate in biology class.

To understand the role of disciplines in epistemological framing in this paper we will consider how epistemological resources at different levels interact-including abstract ideas about the nature of physics and biology knowledge, prior experiences in disciplinary learning environments, and how disciplinarity is presented in the current setting.

\section{E. Summary of theory section}

Drawing on the above sections, we can now consider the potential for epistemological progress in a physics course to influence epistemological framing in a biology course.

First, we can understand epistemological progress in a physics class to entail an increase in the frequency and duration of productive framings for learning physics. If there are epistemological similarities across disciplinary contexts, we might expect students to activate productive framings from one context in the other. This process may be passive, driven by similarity in epistemological messages and cues or actively initiated by a student who sees epistemological similarity across contexts.

It is against this backdrop that we now turn to the case study of Phillip. Phillip, as we have already mentioned, saw connections between physics and biology before he began his undergraduate introductory physics course. Therefore, we might expect that he would be well positioned to actively apply the epistemological frames he was activating in physics class to his biology classes. Moreover, Phillip was in a physics class for life science students, a context designed to create connections between the two disciplines. That Phillip ended the year highlighting the differences between learning in physics and biology requires further consideration. We present Phillip's case next and then return to a discussion of how this case informs our understanding of the impacts of epistemological reforms across contexts.

\section{THE PHILLIP CASE}

\section{A. Study context}

We studied Phillip in the context of a two-semester introductory physics course for the life sciences (IPLS) course called NEXUS/Physics [18]. NEXUS/Physics was designed as part of The National Experiment in Undergraduate Science Education-Project NEXUSfunded by a grant from the Howard Hughes Medical Institute (HHMI) to make physics more relevant to the needs and interests of life science students. The course structure consisted of three 50-minute lectures, one 50minute discussion section, and a 2-hour lab section per week. The course was designed by an interdisciplinary team of scientists and education researchers and iteratively refined in response to data collected by the research team.

The course design was modeled after the epistemologically reformed introductory physics course designed to foreground coherence and sense making [6]. For example, the course featured an assessment structure that rewarded student reasoning, not just canonical correctness, and encouraged students to submit a request for a regrade if they could defend their reasoning. In place of a standard text, course readings were posted online by the instructor. Readings emphasized conceptual understanding, and students were asked to post comments or questions about the readings each week. One of the major changes in the course was in the selection of content that would be relevant to biologists and in the design of recitation problems that were designed to build on students' prior biology knowledge [41].

As part of the project we collected MPEX II scores from students in the NEXUS/Physics course (Fig. 1). The original MPEX II is comprised of three item clusters each related to goals of epistemological reform: (i) coherence items concern expectations about knowledge in physics as interrelated and consistent as opposed to fragmented. Disagreement with the following item is considered favorable in this cluster: "When solving problems, the key thing is knowing the methods for addressing each particular type of question. Understanding the 'big ideas' might be helpful for specially-written essay questions, but not for regular physics problems."; (ii) concepts items probe expectations about the importance of conceptual understanding over memorization. Disagreement with the following item is desirable: "In this course, adept use of formulas is the main thing needed to solve physics problems effectively"; (iii) independence items probe expectations of learning independent of authority. Disagreement with the following item is considered desirable: "My grade in this course will 


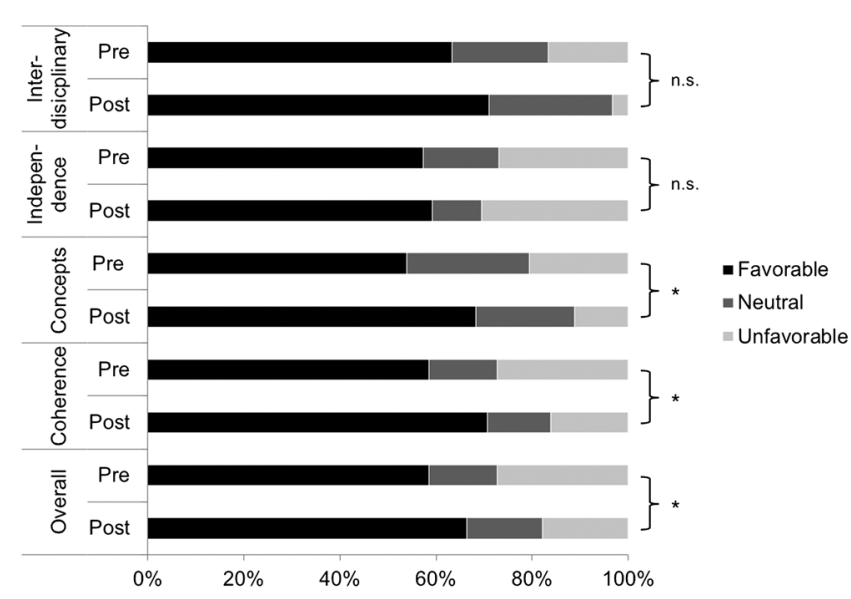

FIG. 1. NEXUS/Physics MPEX II responses for matched students $(n=9)$ in Fall 2012 semester. Asterisk indicates $p<0.05$. Wilcoxon signed-rank test (two-tailed) for overall (28 items), $S=1906, p=0.02$; coherence (11 items), $S=$ 582, $p=0.002$; concepts (7 items), $S=418, p=0.0003$; independence (12 items), $S=-221, p=0.33$; interdisciplinary (10 items), $S=150, p=0.45$.

be primarily determined by how familiar I am with the material. Insight or creativity will have little to do with it." (For more information on clusters see Ref. [12]).

To compare pretest and post-test responses we collapsed the 5-point Likert responses into three categories and assigned a value of 1 to favorable responses, 0 for neutral, and -1 for unfavorable responses. Sixteen students were enrolled in the course, and we had complete matched data for nine students. We compared matched responses using a Wilcoxon signed rank test (Fig. 1) and found higher rankings (due to shifts in the favorable direction) for the coherence cluster $(S=582, p=0.002)$, the concepts cluster $(S=418, p=0.003)$, and for the MPEX II overall $(S=1906, p=0.02)$.
Given that unreformed courses have tended to register negative shifts in the MPEX II [10], the positive shift measured in the fall semester course is an indicator that students generally recognized NEXUS/Physics as aligning with the aims of epistemological reforms, particularly in the dimensions of seeking coherence and focusing on conceptual understanding.

Along with the MPEX II we also piloted a new "interdisciplinary" cluster of questions that asked students about expected connections among disciplines, such as "Ideas I learned in physics are rarely useful in biology." (see Table IV in the Appendix). A Wilcoxon sign-ranked test indicated no statistical difference between pretest and posttest responses $(S=150, p=0.45)$, though the relatively high percentage of favorable responses $(63 \%$ in the pretest and $71 \%$ in the posttest) suggests that the expectation that the disciplines would be related in this course was not violated.

\section{B. Introducing Phillip}

Phillip was enrolled in the second iteration of the NEXUS/ Physics course and was one of 12 students who we interviewed about their experiences in the course. Like most of the students in the course, Phillip enrolled in NEXUS/ Physics as a junior biology major who had taken courses in biology and chemistry in his first two years, but had not taken physics since high school. Figure 2 illustrates the other science and mathematics courses in which Phillip was enrolled both prior to and concurrent with NEXUS/Physics.

\section{Methodological approach \\ 1. Interview data}

We use interview data to support our claims about how Phillip's framing of his physics and biology courses shifted over the year. Phillip was interviewed 4 times over the

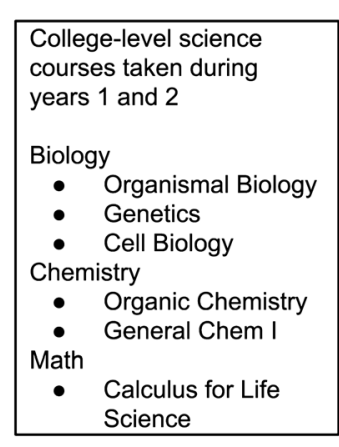

Fall 2010 - Fall 2011
*Summer 2011 and 2012 research assistant in entomology lab

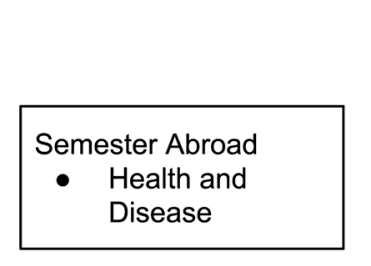

Spring 2012

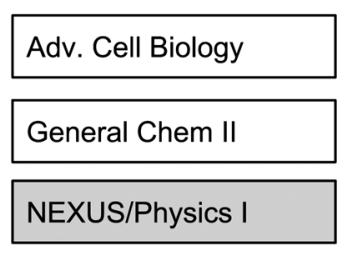

Fall 2012

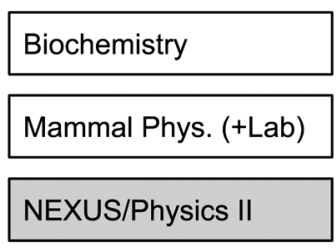

Spring 2013

\begin{tabular}{ll|l|l|l}
\hline & & & & \\
& Interview 1 & Interview 2 & Interview 3 & Interview 4 \\
Aug 2012 & Nov 2012 & Mar 2013 & May 2013 \\
(Card sort) & & & (Card sort)
\end{tabular}

FIG. 2. Science and mathematics courses that Phillip took prior to and concurrent with NEXUS/Physics. 
course of the 2012-2013 academic year (Fig. 2). All four interviews were conducted by the second author and were designed to probe students' perceptions about the differences and similarities between the science disciplines of physics, chemistry, and biology and learning in those courses. We were interested in documenting if students perceived their educational experiences as connected or fragmented. The interview prompts were designed to give students multiple opportunities to reflect on and describe the similarities between the disciplines. Two different protocols were used across the interviews. The presemester and postsemester interviews were centered on a card sort task, and the midsemester interviews were more open ended. Each is described in more detail below.

(a) Card sort interviews.-Card sort interviews were structured in a standardized way with a clear ordering to the questions and an activity built into the middle, which we refer to as the card sort task. The interviews had three main parts: (i) a conversational style set of questions about students' background, interest, and expectations for similarities and differences between the disciplines; (ii) the card sort task described in more detail below; and (iii) questions about expectations of the physics class they were about to enroll in (or had just completed).

The card sort task gave students three different $6 \times 8$ inch colored cards and asked them to write out the "big ideas" of chemistry, biology, and physics separately on the three cards. Then students were asked to think about which of the ideas relate to one another and whether any big ideas span across the disciplines. This task was repeated in asking about "kinds of thinking" that occur in each discipline with follow-ups around what "counts as a good answer to a question" in each of those disciplines. The pre- and postversion of these interviews were conducted in a standardized way in order to compare the card sort task responses before students started in the physics course and after they completed the course. The pre-interview occurred in the week before students started the NEXUS/Physics course and the postinterview occurred in the week of final exams.

(b) Semistructured interviews.- The midsemester interviews focused more on students' experiences in the physics course, and were conducted in a conversational, semistructured style. Questions focused on how students' impressions of the course had changed, as well as impressions about particular interdisciplinary problems and exam questions. Throughout the interview we probed exemplars of physics reasoning, biology reasoning, and connections between disciplinary courses.

\section{Using Phillip's interviews to infer epistemological framings}

There are several features of these four interviews that make them useful for understanding Phillip's epistemological framing. The first is that Phillip was open and articulate about his ideas about knowing and learning. Second, there is evidence that Phillip was actively reflecting on knowing and learning through his course experiences. During the interviews, Phillip described specific examples of his own activities and course structures including details about course assignments, instructor expectations, and exams to support his interpretations. Consider the following example from Phillip's November interview:

Vashti: Ok, let's talk a little about the physics class then. So we talked before the class even started. So I was wondering if you could reflect back a little bit about how you thought was going to be happening in this course would be and how it matches with your actually experience.

Phillip: I think I might have said something about how I expected this to be like more conceptual, and it has kind of been that way, 'cause I really like, in class I don't ever take notes; I just kind of listen to what he says 'cause I don't really see the point of taking notes. Because like every time we have a clicker or something, it's like a different situation. So you can't have notes on like a specific situation because it's not going to help you when you are presented with a new situation. So it's kind of like understanding like what these equations are saying and how it relates to a real life situation. And I think that's kind of what I was expecting and that's kind of how it's turned out as well.

In this excerpt Phillip recalls his past description of physics as "conceptual." Phillip's elaboration on his behaviors in class helps us interpret what he means by this. Phillip links conceptual with specific behaviors and not others. Conceptual does not mean taking notes as the professor is talking; rather, conceptual means listening for meaning. He further elaborates by describing the situation of learning about an equation and describes trying to understand what the equation means in terms of "a reallife situation." This description suggests that Phillip is framing his physics knowledge as sensible and connected to real life. This excerpt also highlights a specific feature of the learning environment that Phillip sees as aligned with that framing: the use of clicker questions that present novel situations. Finally, this excerpt tells us something about the dynamics of Phillip's framing; his reference to his prior expectation suggests that this is not an entirely new way of thinking about knowledge and learning in physics.

What the interview data provide are an account of Phillip's framing from his perspective. We are inclined to believe that Phillip's account is representative of his actual experience in part because as researchers embedded in the course we directly observed Phillip engaging in many of the behaviors he describes-such as arguing over ideas with peers during class and asking the instructor and teaching assistant (TA) for alternative explanations. Given the dynamic nature of framing it is certainly possible that there were moments in his various classes where Phillip could have been experiencing something different 
from what he recalls in the interview. However, because we are interested in tracking broad shifts in framing over the timescale of a year, we find it appropriate to rely on Phillip's own account.

\section{Analytic process}

In our analysis of Phillip's four interviews, we first read through the transcripts to begin to identify epistemological themes that he attributed to his physics and biology courses. For each interview we tagged moments of the interview that related to the nature or structure of knowledge in the course or discipline (e.g., "this course is conceptual" or "in physics you have to know a lot of equations"), approaches to learning (e.g., "I don't even take notes" or "I go through the slides"), perceptions of what is valued from the course context ("I think biology, the best answer is the right answer"), and finally any explicit or implicit connections or disconnections between the disciplines or courses ("all research in science has similarities").

To track Phillip's epistemological progress, we further categorized his comments using commonly valued beliefs about knowledge and knowing in physics: (i) knowledge as coherent as opposed to fragmented, (ii) knowledge as conceptually sensible as opposed to meaningless, and (iii) ideas about knowing as requiring construction and independent effort [5-7]. Note that comments could be and often were placed in multiple categories. For example, the quotation in Sec. III C 2 above contains evidence of valuing coherence (specific situations should relate) as well as conceptual understanding (equations have meaning).

Lastly, we traced themes through the dataset longitudinally and across categories to characterize shifts and consistencies in framings across the year. For example, during the first interview Phillip described his uncertainty around the role of equations in physics course. We therefore traced this thread through each subsequent interview to look for examples of how Phillip talked about equations over time. In this specific case we found evidence of a shift: Phillip was uncertain whether to treat equations as conceptual or as objects to memorize early on, but later he consistently talked about equations as having meaning that he could understand and apply.

In our results we describe patterns of shift in Phillip's framing of physics, biology, and the connections between the two.

\section{RESULTS: PHILLIP'S EPISTEMOLOGICAL FRAMING OF THE DISCIPLINES}

\section{A. Phillip initially frames biology and physics as connected}

In the first interview, which took place before the semester started, Phillip was asked to explore how the scientific disciplines and his scientific coursework have been related. Two aspects of how Phillip describes this relationship stand out from this interview. The first concerns how Phillip frames connections among scientific disciplines and the second concerns how Phillip relates learning across scientific disciplines. Both contribute to an overall initial framing of physics and biology as related under the larger umbrella of science.

\section{Phillip expects connections across scientific subdisciplines}

One of the first questions the interviewer asks Phillip is whether the science courses he has been taking "relate to each other." Phillip begins by describing a connection between his Calculus for Life Sciences class (Calc2) and Genetics. He then goes on to express that there should be more connection, appealing to a general relatedness across all of the sciences:

Phillip: We did a unit on probability in Calc2, and in genetics there was tons of probability, but I had kind of already had some of that, 'cause I took it. But other than that not too much crossover. It would be nice if there was more.

Vashti: Do you think that they should?

Phillip: Oh definitely yeah. It definitely helps you understand the other subject if you are learning it in the other one and can see the relation between them. Vashti: And do you think there is relation and it's just not-?

Phillip: Definitely, yeah. Definitely.

Vashti: Can you elaborate a little more on that?

Phillip: It's just all of the sciences are kind of related to each other. It just makes sense. I don't know how to explain it, but you know, it-they just are [laughs]

Part of Phillip's response is about learning: the idea that seeing the relation between concepts in different courses could support understanding (which we will return to in the next section), but in the last part of the response Phillip shifts to talking about relatedness among "the sciences." Here Phillip communicates that he expects a relationship among scientific disciplines even if it is not represented in his classes. In this moment Phillip presents the idea that the sciences are related as self-evident - "they just are" - but does not provide a more specific description of this relationship.

A few minutes later, the interviewer prompts Phillip to revisit this idea to tell her "a little bit more about how they relate." In response, Phillip offers two different ideas. One idea relates the scientific process in each discipline:

I would say (1s) from like a research perspective or a lab perspective, it is probably really similar, like follow these directions, this is kind of what we are going for, make sure you take your data, conclusions, that kind of stuff.

While it is not clear whether Phillip means to be talking about his expectations of a research lab or an instructional 
lab, he is indicating some expectation that both disciplines involve a common scientific process of taking data and drawing conclusions.

A second idea Phillip proposes is that biology uses principles from chemistry and physics to explain biological phenomena. He offers an example of how the packaging of biomolecules in a cell could be explained in terms of ideas about molecules from chemistry and ideas about bond energies from physics:

I think its more of just like (1s) I think biology is a like a really-biology takes things from physics and chemistry to kind of explain things that are in biology. And I can't really think of an example right now. But just like (2s) let me think about this. Like for example in cell bio we learned a lot about the packaging of like sugars and fats and whatever. And we kind of learned about their structure, and you can definitely see how that could related to even physics or chemistry, because in chemistry we learn about like molecules and what not and then in chemistry [physics] we learn about all the bonding and the energies of them. Did I just say chemistry twice?

In this and other moments in this first interview Phillip positions biology as "taking" ideas from chemistry and physics. He later explains that he is unsure whether it could work the other way, that is, whether physics or chemistry could use ideas developed in biology. In part this seems to be an issue of scale; Phillip explains that it makes sense for disciplines that study things at a smaller scale to be used to explain larger scale phenomena. Thus, physics and chemistry can help explain larger scale biological phenomena, but not the reverse.

Finally, with prompting from the interviewer to consider whether there are any connections among the "big ideas" in each discipline, Phillip identifies a number of concepts that he identifies as spanning the disciplines: specifically entropy and energy.

Overall, in Phillip's first interview there is evidence that Phillip is framing the scientific disciplines as broadly related. He seems relatively certain that the sciences can and should connect. There is also evidence, in the effort it takes to provide examples, Phillip's frequent pauses, and his remarking on these being "tough questions," that Phillip has not given much conscious thought to these ideas before this interview. He does not have ready examples to back up his sense that the disciplines relate but appears to be exploring possible connections in response to being asked to do so in the interview.

\section{Phillip frames learning science as primarily about learning for understanding}

Another connection that Phillip describes in this first interview is that he approaches learning science very similarly across his science courses. Phillip describes himself as a student who prefers to learn for "understanding":

A lot people think that chemistry is memorization or like biology is memorization, but I never saw it like that. I kind of saw it as understanding the big picture and understanding how each thing works, and not just like memorizing it. Because I had a lot of friends who just get note cards for or go and just go through reaction after reaction memorizing them, and I kind of found it better for both biology and chemistry to just understand why things are happening and like why this is the way it is. And I think even for physics that will definitely work. Even though there's lots of equations, and people say you should memorize this and you should memorize that, but like understanding why this equation is the way it is.

In this quote and throughout the interview, Phillip describes "learning for understanding" as central to how he thinks about learning in science. In fact, Phillip attributes his interest in science as related to "understanding how things work." Phillip distances himself from other students who use note cards to memorize, emphasizing that from his perspective, learning for understanding is a better approach. Later, Phillip elaborates on how reading his organic chemistry textbook provided him with understanding because it explained, "why a hydrogen atom adds to this carbon and not that carbon, or why it would form a double bond." It is more interesting to him to understand "why it happens, not just that it happens."

Phillip expects that he may be able to avoid having to memorize in physics as well, though he is unsure. He later elaborates that his uncertainty over what approach he will need to take stems from his lack of experience with collegelevel physics. Phillip is a junior in college and has not taken physics since high school, and, as we will explain in the next section, his experience learning physics in high school was mixed. In particular, Phillip is concerned that if college-level physics has the same focus on equations that high school physics did, then memorizing might actually be a more appropriate approach than understanding. Still, he seems hopeful that even if there are equations he will be able to find a way to understand what they mean, not just memorize them.

Overall, Phillip emphasizes the similarities in how he expects to approach learning across his science courses. Yet, while he is clear that using note cards to memorize is not learning for understanding, he does not provide many details about what learning for understanding looks like in terms of his actual behaviors. What we can say is that Phillip is generally framing learning across his science courses as more similar than different.

\section{B. Phillip's epistemological framing of learning physics becomes more sophisticated}

From the beginning to the end of the year, Phillip's epistemological framing of physics becomes more 
sophisticated. Recall that in the context of a physics course, we have defined sophistication as alignment with the epistemic principles valued by the implementers of epistemological reforms. Across Phillip's interviews we see increasing alignment with and coherence among these principles in Phillip's framing. This pattern also mirrors a shift in Phillip's individual responses to the MPEX II over the year.

\section{Phillip's initial framing of learning in physics is mixed}

During the first interview Phillip describes two contrasting approaches to learning physics: one involves memorizing equations and algorithmic problem solving, the second involves working to understand concepts and theories. Phillip aligns himself with each perspective at different moments in the interview. As we saw above [in Sec. IVA 2], when Phillip first described learning for understanding in biology and chemistry he added "And I think even for physics that will definitely work. Even though there's lots of equations and people say you should memorize this and you should memorize that, but like understanding why this equation is the way it is." Phillip continued, recalling an experience from his high school physics class,

In high school our teacher would work us through the equation so if we forgot the equation he would be like, this is why it is, and if you don't remember it, you work yourself through it. And then you can remember it on the test or something like that 'cause you know why it's this way.

In this example Phillip recalls his high school teacher explaining the meaning of an equation so that, in Phillip's memory, they would be better able to remember it for the test. In this interview Phillip is activating the epistemological resource that equations can have meaning to support his expectation that learning for understanding should be possible in physics.
Later in the interview however, Phillip says that if there were many equations he "would definitely" memorize:

Phillip: For physics, I kind of know it has like the reputation for like memorizing, and I like, I would definitely do it, just because there are like a lot of formulas in it, as compared to like biology, or at least the biology courses I've taken-there's not like that many equations that we've had to learn so far. But I think physics, like, it's a lot more useful there, just because there are those equations.

Vashti: What's useful?

Phillip: Like memorizing

Both resources, that equations have meaning and that equations are objects to memorize are active for Phillip in this interview, which is why we describe his initial framing of learning physics as mixed. At the moment, Phillip does not have enough information about the pending context to decide which approach will be most relevant.

\section{Phillip's framing becomes aligned with the goals of the reformed physics course}

In the remaining three interviews, conducted in November, March, and May, Phillip's framing becomes more aligned with many of the goals of the reformed course. In Table I we present representative quotes that illustrate this alignment.

Phillip consistently describes learning physics as understanding concepts in a way that makes sense to him. Specifically, across all three interviews Phillip never again mentions memorizing equations. Instead, Phillip made statements that suggest his approach to learning involved seeking meaning represented in the equations he was learning (Table I). When asked about a specific example of how he studied for an exam Phillip described how he made sense of the equation for pressure exerted by a fluid:

TABLE I. Phillip's framing aligns with the epistemological aims of the reformed physics course.

\begin{tabular}{|c|c|}
\hline Epistemological category & Example quotation \\
\hline Seeking meaning & $\begin{array}{l}\text { I don't ever take notes. I just kind of listen to what he says cause I don't really see the point of taking } \\
\text { notes. Because like every time we have a clicker or something, it's like a different situation. So you } \\
\text { can't have notes on like a specific situation because it's not going to help you when you are presented } \\
\text { with a new situation so it's kind of like understanding like what these equations are saying and how it } \\
\text { relates to a real life situation. [November] }\end{array}$ \\
\hline $\begin{array}{l}\text { Coherence or reconciling } \\
\text { perspectives }\end{array}$ & $\begin{array}{l}\text { I liked being able to like link the ideas together. And I think this is kind of how the class [lecture] is too. } \\
\text { Like when we have our discussions it's like some people get it one way and then some people } \\
\text { understand it the other way and then it's like how do you link these ideas. [November] } \\
\text { [the TA] is very helpful too with how she explains things it's always nice to get like a different um } \\
\text { explanation of something so I do ask her questions and like I go to office hours a lot too just to get her } \\
\text { way of thinking about something differently. [March] }\end{array}$ \\
\hline Construction or effort & $\begin{array}{l}\text { Obviously most of the time you are not going to get something the first time. [March] } \\
\text { you'll have a question that's really like, like open I guess, and it's not as like obvious what the answer is, } \\
\text { and it's not as clear as what the direction you should take is, and then it's like ok, using what you have } \\
\text { learned in class how can you apply what you know to this question and figure it out that way. [May] }\end{array}$ \\
\hline
\end{tabular}


Phillip: The pressure equals p-naught plus density times gravity times the depth. I don't think we actually had to use it on exam 2, but just knowing what all those the factors mean: Like dis the depth of the object, $g$ is gravity, rho is the density of the liquid it's in, so just knowing all of that what they mean instead of just the letters.

Vashti: So did you mostly focus on equations or what's inside the equations to prepare?

Phillip: I think I focused more on what's inside the equation and if you were to increase one how that would affect something else in the equation. I think the readings and going over the readings and looking at what they say about the equation kind of helps too because the readings kind of work you through it, they kind of derive it or something an I felt like that is helpful for understand the equation too. So I did a lot of reading to make sure I understand how they go to this point.

In this example and others throughout the three interviews Phillip references the physical meaning in equations and how he strives to understand them. He describes both understanding what the individual symbols refer to in the world and thinking through the relationships among them. $\mathrm{He}$ also describes his specific use of readings to help him understand how the equations were derived. These specifics indicate a framing of equations as having meaning that is well linked to concrete strategies for learning.

Another common theme across the interviews was coherence, what Phillip describes as "links" between ideas, and the related process of reconciliation (Table I). Phillip identifies the instructor's emphasis on reconciling different perspectives to be particularly useful for his understanding of how different ideas fit together. He also provides two examples of his own practice of reconciliation. He describes working with a classmate who thinks differently from him and intentionally seeking out the TA in office hours because she often presents him with a different way to think about a problem.

In addition, Phillip describes thinking and learning in physics as requiring effort both in moments to construct understandings and over time. Phillip describes not expecting to immediately know the answer to a problem. Instead, he must engage in what he calls "reasoning" to "apply what you know" and "figure out a way" forward (Table I). Phillip describes the process of coming to understand ideas as spanning multiple days or even weeks. He admits that often he does not understand the prelecture readings, but that his understanding builds as he listens and engages in discussion in class and works problems in office hours with his peers and the TA.

Overall, compared to Phillip's initial framing of physics as possibly about memorizing, or possibly about understanding, this new framing is a significant shift. It is both well integrated and specific, and it contains clear descriptions of how Phillip has implemented these ideas in his approach to learning physics. This shift is also mirrored in Phillip's responses to the MPEX II over the year.

\section{Phillip's MPEX II responses over the year}

Overall Phillip's responses to the MPEX II survey show a tendency to choose more favorable and fewer unfavorable responses from pre to post (Table II). This pattern generally aligns with some of the shifts that are evident in Phillip's interview responses.

More specifically, the questions that flipped in the favorable direction align with some of the specific points Phillip made in interviews. For example, in the concepts cluster Phillip initially agreed that, "In this course, adept use of formulas is the main thing needed to solve physics problems effectively," but then chose "neutral" at the end of the year. He also originally chose neutral in response to the question, "Problem solving in physics basically means matching problems with facts or equations and then substituting values to get a number," but shifted to "disagree" at the end of the year. These shifts correspond with Phillip's initial concerns that he might need to memorize equations to be able to use them to solve problems.

In the coherence cluster Phillip's response changed from neutral to disagree for the following prompt: "When solving problems, the key thing is knowing the methods for addressing each particular type of question. Understanding the 'big ideas' might be helpful for specially-written essay questions, but not for regular physics problems." This response mirrors Phillip's description of the utility of understanding "foothold principles" that can be applied to many problems.

Finally, in the independence cluster Phillip flipped his response to from "agree" to "disagree" on the following prompt: "My grade in this course will be primarily determined by how familiar I am with the material.

TABLE II. Phillip's responses on the MPEX II and interdisciplinary cluster (42 items) from Pre (August 2012) to Post (May 2013). Note that items can belong to more than one cluster (with the exception of the interdisciplinary cluster); therefore, the sum of cluster items is greater than the overall number of items.

\begin{tabular}{lcrr}
\hline \hline MPEX cluster & Response & Pre & Post \\
\hline Overall & Fav & 20 & 22 \\
& Neutral & 9 & 10 \\
Coherence & Unfav & 13 & 10 \\
& Fav & 4 & 6 \\
& Neutral & 6 & 3 \\
Concepts & Unfav & 1 & 2 \\
& Fav & 1 & 4 \\
Independence & Neutral & 4 & 3 \\
& Unfav & 2 & 0 \\
Interdisciplinary & Fav & 5 & 6 \\
& Neutral & 1 & 1 \\
& Unfav & 6 & 5 \\
& Fav & 8 & 7 \\
& Neutral & 0 & 1 \\
\hline \hline
\end{tabular}


Insight or creativity will have little to do with it." This response aligns with Phillip's emphasis on reasoning to solve novel problems in his interviews.

\section{Phillip's framing scientific disciplines as related remains consistent over the year}

Phillip repeats and elaborates on the possible connections among the disciplines that he raised in the first interview in the remaining interviews. In March, Phillip revisits the idea that the disciplines are similar methodologically:

Um I think most research is the same in the sense that there is something you are investigating and you want to like do experiments or tests or whatever or like look at um like certain data or whatever that helps you like refute or maybe prove or like say something might be true. And like it doesn't matter if you are doing entomology research, which is kind of like a lot of field data collection, or sitting in a lab and looking in a microscope, like the general idea is that you are gathering data to help back something up or like help prove something and then in physics it is kind of like that too.

In this example, Phillip is referring to his own experience working as a research assistant in biology labs (an entomology lab over the summer and doing microscopy in the fall, Fig. 2) to speak broadly about the similarities in all scientific research. Even though Phillip acknowledges that the specific methods differ (i.e., field work or microscopy), he claims that all scientific research has a similar structure of gathering data that can potentially back up hypotheses or serve as proof.

Phillip also revisits ideas about the explanatory structure among the disciplines. In the March interview, Phillip draws a diagram that placed biology above physics and chemistry with arrows leading from physics and chemistry to biology (Fig. 3). He explained,

I always, I've always thought that everything in biology happens because of physics and chemistry because of interactions between like molecules and whatever, that whole thing. Like so I've never seen biology as it's like own thing. I kind of see it as like it's come out of chemistry and physics.

Here Phillip positions chemistry and physics as the explanatory foundation for biology. Biology is not "it's

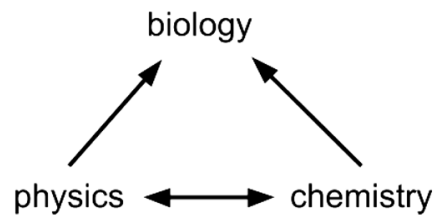

FIG. 3. A recreation of Phillip's drawing depicting the relationship among the disciplines. own thing," but rather depends on physics and chemistry to help explain it by providing the "why" things happen. This idea, as it was in the first interview, is related to phenomena at the molecular level where chemistry and physics provide a way to understand molecular interactions. He positions biology as interested primarily in the phenomena themselves. For example, when discussing protein folding in the November interview, he describes biology professors as uninterested in "what is causing it to happen; they just want you to know that it happens."

While this is a common way for Phillip to describe the explanatory structure of the disciplines, it is not the only way. He describes biology as more autonomous from physics, particularly at larger grain sizes of populations and ecology:

But I think at times bio can be different than physics. You don't need to understand some things in physics. It just helps you, like it helps you have like a better, like a more complete understanding. But like to understand something you don't really need to know about physics. Like when you talk about extinction stuff, like natural selection, you don't necessarily need to know about physics.

Here Phillip makes a distinction among subdisciplines within biology. Physics can help explain smaller-scale phenomena in biochemistry and physiology where Phillip can see how principles from physics and chemistry would apply, but some areas of biology are more autonomous, they don't rely on physics to provide the explanatory foundation.

Finally, as in the first interview, Phillip identifies various conceptual connections among the disciplines. Once again his main focus is on energy and entropy. "Entropy" Phillip says is "everywhere." He also makes many additional links that he did not make in the first interview. For example, he links electricity to cells, and neurons specifically. He relates Newton's laws to "everything except on a really small scale" (by small scale he means protons and neutrons).

Overall, though from the initial August interview through the end of the academic year, how Phillip describes relationships among the scientific disciplines does not appear to have changed very much. He consistently describes all science as united under a general umbrella of scientific processes, and he expects and can identify areas of conceptual overlap. He also consistently positions physics and chemistry as foundational to explaining many phenomena in biology, though he also acknowledges that there are some areas of biology that are more independent of physics and chemistry.

\section{Phillip's framing of learning physics and learning biology diverges}

While Phillip's framing of the disciplines themselves has not changed very much, Phillip's framing of leaning in different disciplinary courses shifts rather dramatically. 
At the beginning of the year Phillip described his preferred approach to learning across his science courses as focused on understanding. While he was confident that this approach to learning was successful in chemistry and biology, he was unsure whether or not it would be valued in physics.

Phillip found his physics course to be very much aligned with learning for understanding and, in fact, Phillip's approach to learning in physics became aligned with specific epistemic principles like sense-making and coherence. He also developed a set of strategies for learning in physics (summarized with examples in Table III) such as discussing with peers, seeking out alternative explanations from his TA, reading prior to lecture and listening for understanding rather than simply copying down whatever the instructor said.

We have described this as a shift towards sophistication in Phillip's framing of learning in physics. We now describe how Phillip's framing of learning in biology shifted in a different direction.

The most dramatic evidence of a shift takes place in the final interview in May. Phillip begins by describing his shift in physics; his concern that physics could be more formula based did not come true. Instead he describes learning physics, like biology and chemistry, as thinking and using reason:

Before I would taken this class, I would have thought physics is more like mathematical formula-based, like here is a formula and it somehow tells you what this means. But now, like in this class, it's not taught that way. So it's more like think about it, like with reason, not just with a formula. And I think that is how like biology and chemistry are, is, you have to think about it in a reasonable way and use reason to figure things out.

Phillip continues to talk about his dislike of memorizing and how he was able to avoid it in his physics class, when he suddenly reverses his description of biology, calling out the amount of memorizing he does,

Phillip: And (1s) I don't know I think it's more like the opposite now (laughing) because in biology I do a lot more memorizing than I do in physics which is, I don't know, interesting. So I guess that's a big difference is that like in biology I feel like I just memorize things. Like you just need to know this is happening this is why it happens, but then like physics it's like you need to reason your way through it. Like and there is still that aspect of like using formulas and whatnot but you have to like know the reasons why you are using that formula I guess yeah.

Vashti: So you said, um when you started you said before I took this class I would have said something, and then you said now it's opposite, so I am curious whether you think your biology experience have [sic] also changed that it's now more memorizing or do you think your perspective on which one is memorizing has changed?

Phillip: I think it's more perspective. 'Cause I think I have been memorizing this whole time even though I think I am understanding it. But like I mean there are certain things where you kind of have to understand it, but there's a lot where you are like, just like know it [hits palm with back of hand]. (laughs) So I think when I look back on it now I am like yeah, (nodding) it's a lot of memorization.

In this moment Phillip not only shifts how he is describing his current experiences learning biology, he also reinterprets his past experiences. Previously Phillip thought of himself as understanding, but now, looking back he believes that "he has been memorizing this whole time."

While this realization seems abrupt in the moment, it is consistent with some of what Phillip has been saying throughout the year about his approach to learning in the two instructional contexts (Table III). For instance, in November Phillip admitted that he does have to memorize some of the time:

Phillip: I mean that depends on the class too 'cause obviously there is some memorization in some classes. Like I had to memorize amino acids for biochem. Like there is really no way to get around that, you just have to know it, so. But I have always kind of been someone that tries to understand things like how, why things are happening, than memorize. Which is why I like the biochem class because you are understanding why things are happening.

Vashti: So you don't see that as being a lot of memorizing even though you might memorize some things.

Phillip: Yeah there are some things that's memorizing, but most of it's definitely understanding.

What makes the May interview so different is that in other interviews Phillip would frame memorizing as relatively rare. He would identify isolated instances of needing to memorize amino acids or having to know particular terms for an exam, but he would downplay these moments or reinterpret them. For example, in the August interview Phillip described his knowledge of the grading strategy in his biology courses as focused on identifying "keywords." While it would be possible to interpret this grading approach as valuing memorizing terms, Phillip explained that the while it is true that TAs are looking for keywords, they are doing this to check for understanding. Keywords are "the cues to them that you're on the right track. And then they make sure that you are actually talking about what you're talking about."

In this final interview Phillip shifts his interpretation of these experiences, now categorizing them as something different. This shift occurs at approximately ten minutes 
TABLE III. Phillip's approach to learning in his physics and biology classes.

\begin{tabular}{|c|c|c|}
\hline & NEXUS/Physics class & Biology classes \\
\hline \multirow[t]{2}{*}{$\begin{array}{l}\text { Preparing } \\
\quad \text { for exams }\end{array}$} & $\begin{array}{l}\text { I did the practice problems and I went to office } \\
\text { hours and I ... looked over the readings. ... } \\
\text { I looked over clicker questions to see if I would } \\
\text { use the equation make sense of it. [Nov] }\end{array}$ & $\begin{array}{l}\text { I have this strategy where I put up my computer, } \\
\text { and then I put the slides, and I have my textbook. } \\
\text { And I kind of go through the slides, cause he focuses } \\
\text { a lot on the diagrams and being able to work through } \\
\text { the steps, and knowing what every protein at every } \\
\text { step is doing and how it gets there. [Nov] }\end{array}$ \\
\hline & $\begin{array}{l}\text { he always puts up the foothold principles, } \\
\text { and I make sure I can understand how } \\
\text { that can be, like how I can apply those } \\
\text { in different situations. Obviously, I don't } \\
\text { know what he is going to ask, but I just } \\
\text { want to make sure I fully understand it. [May] }\end{array}$ & $\begin{array}{l}\text { I just read the book and just like read it and read it } \\
\text { and read it and read it... I am like really like } \\
\text { paying attention like picking out every detail. [May] }\end{array}$ \\
\hline $\begin{array}{l}\text { Interactions } \\
\text { with instructors }\end{array}$ & $\begin{array}{l}\text { I would think this class is where I interact } \\
\text { with my TA the most. [March] }\end{array}$ & $\begin{array}{l}\text { And then biology we have TAs but like it is pretty much } \\
\text { another lecture that he does during discussion } \\
\text { so it's not like a lot of interacting. [March] }\end{array}$ \\
\hline In-class & $\begin{array}{l}\text { in class I don't ever take notes. I just kind } \\
\text { of listen to what he says cause I don't really } \\
\text { see the point of taking notes. Because like } \\
\text { every time we have a clicker or something, } \\
\text { it's like a different situation. So you can't } \\
\text { have notes on like a specific situation because } \\
\text { it's not going to help you when you are } \\
\text { presented with a new situation so it's } \\
\text { kind of like understanding like what these } \\
\text { equations are saying and how it relates } \\
\text { to a real life situation. [Nov] }\end{array}$ & [no data] \\
\hline Readings & $\begin{array}{l}\text { Like when I go through the reading I am like } \\
\text { well I kind of know some stuff about this } \\
\text { and I kind of try to pull from other stuff } \\
\text { when I do the readings. [March] }\end{array}$ & In my other classes I always read after the lectures [May] \\
\hline $\begin{array}{l}\text { Perceptions } \\
\text { of assessments }\end{array}$ & $\begin{array}{l}\text { it's a lot more about the approach and how } \\
\text { you approach the problem.... I mean the right } \\
\text { answer is always a good thing to get, but like } \\
\text { as long as you were thinking about it right, } \\
\text { like and you are showing that you are not } \\
\text { just, like you have no clue, I guess } \\
\text { that's a good answer. [May] }\end{array}$ & $\begin{array}{l}\text { I think biology the best answer is just the right answer. } \\
\text { Like I don't know sometimes they will ask you to } \\
\text { explain, like they will ask you to graph something } \\
\text { and explain why but most of it is just like you } \\
\text { are right or you are wrong. Like its yeah } \\
\text { that's basically it. [May] }\end{array}$ \\
\hline
\end{tabular}

into the interview. Over the remaining 40 minutes, Phillip no longer makes any reference to understanding in biology courses. Instead, he continues to provide other examples that illustrate the differences between his physics and biology classes. He describes his biology courses as presenting "mass knowledge" that you just "have to know"; describes his instructors as "nitpicky" and uninterested in his justifications for his answers because in biology "you are right or you are wrong." In making these comments Phillip makes reference to biology courses in which he is currently enrolled as well as his past coursework (see Fig. 2). That is Phillip is describing his experiences in his biology courses generally, not simply his dissatisfaction with a single course.

In contrast, when describing the NEXUS/Physics course he emphasizes making sure he understands foothold principles and "can apply them in different situations," and the importance of thinking and justifying your answers over needing to be correct. In this final interview Phillip is framing knowing and learning in his biology and physics courses as more different than alike; Physics class is where he uses reason to figure out how the world works; biology classes requires that he take notes, read, and just know it.

\section{DISCUSSION}

In the above we described patterns of framings within Phillip's NEXUS/Physics class, beyond physics, in his biology courses, and of the scientific disciplines. In this section we propose explanations for these patterns in terms of epistemological resources, framing, and transfer. 


\section{A. Accounting for Phillip's progress towards sophistication in NEXUS/Physics}

Phillip's incoming epistemological framing of physics courses included a mix of resources about physics knowledge and learning-some productive from the perspective of epistemological reform and others less so. For example, Phillip clearly understood that equations could have meanings that correspond to the physical world. This was an idea that was reinforced for him in his high school physics class. $\mathrm{He}$ also understood though that physics equations could be treated as objects to memorize and deploy in problem solving. Phillip could have applied either of these resources to learning in the NEXUS/Physics course, but he interpreted the course to be asking him to use equations as tools for thinking about the real world. Phillip came into the course with other productive resources as well: an appreciation that science is about "understanding how things work" and experiences productively linking ideas within and across courses. These resources aligned with the emphasis on physical mechanisms and seeking coherence through reconciling alternative perspectives in NEXUS/Physics.

Generally then, the more sophisticated framing emerged and became stabilized through interactions between Phillip's prior experiences and resources and the course context $[8,14]$. Phillip's personal epistemology of physics at the end of the year consisted of a more well-developed and integrated set of resources that will be more likely to "transfer"-become activated in a coherent way in similar contexts [14]. Were Phillip to enroll in another physics course, he could activate this set of productive epistemological resources. These resources are not a guarantee of sophisticated framings; Were Phillip to find himself faced with a high-stakes exam that required knowing equations and rapidly applying them to solve problems we could imagine him activating latent resources about the utility of memorizing [22].

Of course, Phillip, a biology major, has no plans to take more physics courses, which makes the impact of NEXUS/ Physics beyond physics more important to consider.

\section{B. Accounting for Phillip's shifting interpretation of his biology courses}

In this section we account for Phillips' initial epistemological framing of biology courses and why it shifted at the end of the year.

\section{Phillip's initial framing of learning for understanding in biology}

If Phillip was "memorizing this whole time," then why did he see himself as understanding in his biology courses for most of the year? One possibility is that Phillip's initial descriptions reflected his preference for learning more than his actual experiences. Phillip saw science as "understanding how things work," and identified as a learner who preferred to learn this way. In fact, Phillip was hesitant to call himself a "premed" student because he did not want to be viewed as the kind of student who is just trying to memorize. Learning for understanding seemed to be part of his identity as a learner generally (as in Ref. [42]) and could account for why he applied that framing so broadly.

A possible contributing factor was that Phillip's initial set of resources for "learning for understanding" in biology was not very well defined. Phillip did not provide specific examples of principles or practices from his biology courses that aligned well with an understanding framing. He described what he did not do (use notecards to memorize), but he did not provide examples of how he approached learning for understanding in biology. Instead, when he described practices that seemed to promote memorization, such as TAs "checking for keywords," Phillip tried to fit those examples under the umbrella of understanding; He interpreted checking for keywords as a quick way that TAs could check for deeper understanding. Without a well-defined set of criteria for what counts as learning for understanding, Phillip was able to interpret a range of his experiences through this preferred lens.

A related possibility is that what Phillip meant by understanding at the beginning of the year was different from what he meant at the end of the year. Early on, understanding encompassed knowing. Understanding meant integrating together various pieces of biological knowledge to be able to describe the known steps of some biological process. This is a more sophisticated kind of knowing than simply memorizing the symbols in an equation, but it does not require reasoning or reconciling, only recalling the way the process actually is. Only later, as Phillip began to have different experiences in his physics course, did he begin to narrow his definition of learning for understanding to include opportunities for reasoning and reconciling.

\section{Phillip's shifting interpretation of biology courses}

We initially conjectured that resources Phillip activated in his physics course could lead to activation of similar resources in his biology courses. Perhaps Phillip would focus less on all the details in course readings and begin thinking about biology in terms of organizing principles and reasoning strategies. We did not see this. Instead, resources related to coherence, sense-making, and intellectual effort remained compartmentalized-applied only to his physics course.

What did shift was Phillip's interpretation of learning and knowing in his biology courses. At the beginning of the semester Phillip described biology courses as about understanding, but in his final interview he said that more often he had to "just know it." As Phillip explained in this interview, it was not the courses that had changed from one semester to the next, but rather his perspective that had changed: He saw now that he "had been memorizing this whole time." 
This shift in interpretation can be viewed as a kind of "transfer" of the epistemological resources he strengthened in NEXUS/Physics. The main mechanism is not applying the resources across contexts but using them to interpret one context in light of the other [34,43]. Like the high school students who saw the difference between their physics class and the high stakes exam [22], Phillip came to see a difference in the epistemic demands of his physics and biology courses.

Part of the reason he was able to notice this difference could be that he developed a more specific set of resources and strategies related to learning for "understanding." By the end of the year learning for understanding had become populated with specific behaviors from physics class: seeking meaning in equations, reconciling inconsistencies, reasoning from "foothold" principles. Phillip had developed a more specific template of what it looked like to learn for understanding that had clear ties to the course messages and his own experiences as a learner in NEXUS/Physics. What he was doing in his biology coursework could no longer be fit into this new definition.

It seems likely that participating in interviews in which he was asked to reflect on his coursework contributed to Phillip's developing awareness. Not only did Phillip reflect on what it meant to know and learn in physics, but he was also asked to compare these experiences with knowing and learning in other courses. Phillip would often describe his experiences in biology and physics in quick succession. For example, in the November interview Phillip described studying for his physics exam by working through problems and making sure he understood how to apply the central principles. Just a few minutes later he described how his strategy for studying for biology exams was (and had been) reading through all the slides and "knowing every protein and every step" (Table III).

An alternative, and not mutually exclusive possibility, is that Phillip's biology courses were epistemologically sophisticated in ways that were more difficult for Phillip to perceive or describe. NEXUS/Physics included repeated, explicit messaging about the core epistemological principles. We do not have independent evidence of exactly what Phillip was asked to do in his biology coursework or how the activities or assessments were framed by his instructors. It therefore remains possible (even likely) that Phillip's biology coursework included opportunities to do more than "just know." Nevertheless, it is consequential that Phillip does not see it this way.

\section{Phillip's framing of the scientific disciplines}

In this section we consider how Phillip's framing of the disciplines could have interacted with his framing of his disciplinary coursework. One of the themes that recurred in Phillip's discussion of the disciplines was that biology does not have its own explanatory framework. Phillip said he does not think of biology as "its own thing," but rather a discipline that relies on physics and chemistry to explain it.

This hierarchical positioning of the disciplines could have been reinforced by NEXUS/Physics. The curriculum presented students with biology problems for which physics principles had explanatory power (i.e., diffusion, the spontaneous formation of cell membranes, ATP hydrolysis). These examples were chosen intentionally so that students would see the value of physical principles for reasoning about biological phenomena [41] but may have had the unintended effect of reinforcing reductionist epistemologies. In addition, the physics instructor sometimes emphasized epistemological differences between physics and biology [44]. Physics was described as relying on clean principles and equations that could be used to think and reason. Biology was described as complex and containing many facts that experts know. These messages could have played a role in reinforcing the expectation that principle-based reasoning belongs in physics courses but not biology courses.

We do not know whether Phillip's shifting perception of his biology coursework had anything to do with these more abstract ideas about the disciplines. He never explicitly made that connection himself. Nevertheless, we raise the possibility that this framing of the disciplines could have reinforced Phillip's expectations of his courses: If biology is a discipline that is primarily concerned with describing "what is" then why would students expect to engage in reasoning in their biology courses? All they should need to do, in Phillip's words, is "just know it.",

Recall also that Phillip had resources for seeing the scientific disciplines as connected "from a research perspective" - as broadly about collecting data to test hypotheses. This raises the possibility that Phillip, and other students, may have resources that could be "tapped" into in building epistemological bridges between the disciplines. We elaborate on this possibility in the next section.

\section{IMPLICATIONS AND RECOMMENDATIONS FOR IPLS}

From the perspective of epistemological reform in physics education, Phillip's case can be viewed as a success. Not only did Phillip develop a set of sophisticated epistemological resources productive for learning physics, but he also used that framework to reinterpret the epistemological framing of a course in another discipline - an example of epistemological transfer.

This raises the question of whether a physics course might function more broadly to help science students

\footnotetext{
${ }^{3}$ Of course, this characterization of biology as a discipline that is only concerned with collecting facts to know is as inaccurate as a characterization of physics as a discipline that is only concerned with algorithmic problem solving. Both mischaracterizations confuse unreformed introductory-level coursework with authentic practice in the disciplines.
} 
develop more sophisticated approaches to learning in science (or beyond). Perhaps physics is a discipline that is especially well suited to teaching students about the nature of knowledge in science and how to learn it deeply. After all, Louis learned about the value of sense making across his college coursework, and Phillip developed a suite of approaches to learning for understanding.

Yet there is also something disconcerting about this result. After all, Phillip is a biology major. After taking a year of physics he concluded that the main thing he had been doing in his biology coursework was memorizing. What are the implications of this realization?

It is possible that Phillip's assessment was mostly correct; that the biology courses in which he was enrolled did tend to primarily emphasize recalling facts. This interpretation suggests a need for more research on the epistemic culture of biology courses. Within the biology education community there is a growing recognition that biology courses need epistemological reform to foster for biological thinking as opposed to just knowing facts $[45,46]$.

We want to emphasize another way to think about the implications of this work - as a call to build epistemological connections across college science courses. IPLS courses like NEXUS/Physics have put tremendous energy into shifting the course content to emphasize conceptual connections between physics and biology [18,47-50]. Often these reforms have included ongoing conversations between experts in each discipline to find a balance between teaching concepts that are both central to physics and relevant to biology $[47,48]$. We see an opportunity for additional work aimed at specifically identifying and supporting epistemological connections across science courses. Traditional epistemological reforms in physics have emphasized the utility of teaching students to "think like physicists" [48]. This framing is sensible. The tools that physicists have developed to gain knowledge about the world are powerful. However, we would not want students to see such tools as narrowly applicable only in physics.

It is here that we see a role for Engle's argument for framing for intercontextuality $[19,20]$. Engle argues that learning environments can be intentionally designed to communicate that what is being learned in them is more broadly applicable. Simply having authentic biology content in a physics class does some of this work by communicating that there are authentic links among content domains. In NEXUS/Physics we saw evidence that it helped students draw on knowledge from outside the physics class to make sense of the problems in that class [51,52].

We propose that there may be more explicit epistemological work to do to frame disciplinary contexts as part of a larger scientific endeavor to understand the world. Drawing on Engle's recommendations and our own experience as designers and researchers in NEXUS/Physics, we offer the following recommendations.
(1) Identifying and design for common epistemological principles and practices. For example, in our discussions we identified scientific modeling as a practice common across physics and biology, and one that could be used to foreground epistemological connections (not just differences). It is common in physics to use simple models to gain insight into physical systems. Modeling is a common practice in biology as well $[53,54]$. Even very simple models such as those used in Mendelian genetics, predatorprey interactions, and population genetics can be found in biology. Once principles and practices like these are identified, instructors from across different disciplines can coordinate to support their use across multiple disciplinary courses.

(2) Foreground epistemic value over disciplinary origins. That is, rather than describe problem-solving strategies or ways of thinking as "physics tools," [48] discuss the value and limitations of those approaches for generating and evaluating knowledge. This way the utility of these tools is communicated without narrowly prescribing the bounds of their use. For example, students could be taught to value the practice of estimation for getting a quantitative "sense" for a problem. We would not want students to think about this as a practice they only use in physics class when they are asked to solve a special class of "Fermi" problems.

(3) Notice and build on students' (disciplinary) epistemological resources. Students may bring different epistemological resources to the classroom. Interdisciplinary learning contexts like IPLS courses may elicit a range of different resources inspiring reflection about the nature of knowing and learning in different disciplinary contexts. For example, in prior work [51] we reported on a student named Gregor who was able to articulate the difference in how physics and biology modeled the breaking of a phosphorous bond during ATP hydrolysis. Rather than privilege one approach as correct, Gregor expressed an awareness of the strengths and limitations of different modeling choices. The physics approach focused on in on the energetics at the bond level, while the biology approach contextualized that bond breaking in an aqueous environment, relevant for understanding the energy transformations within organisms. This moment was made possible because Gregor's biology expertise, including his epistemological expertise about system boundaries, was valued in NEXUS/Physics.

This list is just a starting point. We suggest that coordinated instructional reform and research on epistemological framing and development across disciplinary contexts is an important area for future cross-disciplinary collaborations [55]. 


\section{SUMMARY AND CONCLUSION}

We began by highlighting the goal of epistemologically oriented reforms of physics courses to change how students think about knowledge and approach learning in physics. From this perspective, Phillip's case adds to the growing list of examples of the success of these reforms. We then questioned whether the effects of epistemological progress could extend beyond physics courses. Phillip's case illustrates one form such "transfer" can take. Phillip used a newly elaborated set of epistemological resources to reflect on and reinterpret his experiences in his biology courses. In this way, Phillip's physics course contributed to his metacognitive awareness of how knowledge and learning were being presented in his biology courses.

For Phillip's development as an individual learner these are positive outcomes. However, Phillip's case also draws attention to a larger problem with the instructional contexts that students encounter at the university level. Different disciplinary learning environments can communicate different, even conflicting epistemological messages, and we know very little about how students navigate these differences. We therefore conclude by calling on researchers and reformers to consider epistemological development more broadly, as a phenomenon that extends beyond single courses.

\section{ACKNOWLEDGMENTS}

We thank "Phillip" for his participation in this study. We greatly appreciate the feedback on the development of this work from the University of Maryland PERG and BERG. We are particularly grateful for the substantive discussions with and feedback from Benjamin Dreyfus, Benjamin Geller, Chandra Turpen, and Edward (Joe) Redish. We would also like to thank two anonymous reviewers for their insightful comments and suggestions. This work was supported by NSF- TUES DUE 11-22818, the HHMI NEXUS grant, and an Open Access Publishing award from Tufts University.

\section{APPENDIX: INTERDISCIPLINARY CLUSTER}

In Table IV we list the items that comprised the "interdisciplinary" cluster that we piloted in NEXUS/Physics as part of the MPEX II.

TABLE IV. Items from the Interdisciplinary Cluster.

\begin{tabular}{ll}
\hline \hline Subcluster & \multicolumn{1}{c}{ Question prompt } \\
\hline Physics subcluster & Time should not be taken out of physics courses to present biology. \\
& It is beneficial to me, as a biologist, to also be proficient in physics. \\
& Ideas I learned in physics are rarely useful in biology. \\
& Physics helps me make sense of biological phenomena. \\
Ideas I learned in biology are rarely useful in physics. & Physics is largely irrelevant for understanding biological processes. \\
Math Subcluster & Math provides another way of describing biological phenomena, \\
& but rarely provides a deeper or better understanding. \\
& Ideas I learned in math are rarely useful in biology. \\
& It is beneficial to me, as a biologist, to also be proficient in math. \\
& Mathematics helps me make deeper sense of biological phenomena. \\
\hline \hline
\end{tabular}

[1] E. Brewe, L. Kramer, and G. O'Brien, Modeling instruction: Positive attitudinal shifts in introductory physics measured with CLASS, Phys. Rev. ST Phys. Educ. Res. 5, 013102 (2009).

[2] A. Elby, Another reason that physics students learn by rote, Am. J. Phys. 67, S52 (1999).

[3] A. Elby, Helping physics students learn how to learn, Am. J. Phys. 69, S54 (2001).

[4] F. Goldberg, V. Otero, and S. Robinson, Design principles for effective physics instruction: A case from physics and everyday thinking, Am. J. Phys. 78, 1265 (2010).
[5] D. Hammer and A. Elby, Tapping epistemological resources for learning physics, J. Learn. Sci. 12, 53 (2003).

[6] E. F. Redish and D. Hammer, Reinventing college physics for biologists: Explicating an epistemological curriculum, Am. J. Phys. 77, 629 (2009).

[7] D. Hammer, Epistemological beliefs in introductory physics, Cognit. Instr. 12, 151 (1994).

[8] T. Bing and E. F. Redish, Epistemic complexity and the journeyman-expert transition, Phys. Rev. ST Phys. Educ. Res. 8, 010105 (2012). 
[9] J. Tuminaro and E. F. Redish, Elements of a cognitive model of physics problem solving: Epistemic games, Phys. Rev. ST Phys. Educ. Res. 3, 020101 (2007).

[10] E. F. Redish, J. M. Saul, and R. N. Steinberg, Student expectations in introductory physics, Am. J. Phys. 66, 212 (1998).

[11] W. K. Adams, K. Perkins, and N. S. Podolefsky, New instrument for measuring student beliefs about physics and learning physics: The colorado learning attitudes about science survey, Phys. Rev. ST Phys. Educ. Res. 2, 010101 (2006).

[12] T. McCaskey, Ph.D. thesis, University of Maryland, 2009.

[13] A. Madsen, S. B. McKagan, and E. C. Sayre, How physics instruction impacts students' beliefs about learning physics: A meta-analysis of 24 studies, Phys. Rev. ST Phys. Educ. Res. 11, 010115 (2015).

[14] D. Hammer, A. Elby, R. E. Scherr, and E. F. Redish, Resources, framing, and transfer in Transfer of Learning from a Modern Multidisciplinary Perspective, edited by J. Mestre (Information Age Pub, Greenwich, 2005), pp. 89-120.

[15] Retrieved from https://nces.ed.gov/programs/digest/d17/ tables/dt17_322.10.asp?current=yes, 2018.

[16] American Association for the Advancement of Science, Vision and Change in Undergraduate Biology Education: A Call to Action (American Association for the Advancement of Science Press, Washington, DC, 2011).

[17] Howard Hughes Medical Institute-American Association of Medical Colleges Committee, Scientific Foundations for Future Physicians (American Association of Medical Colleges, Washington, DC, 2009).

[18] E. F. Redish, C. Bauer, K. L. Carleton, T. J. Cooke, M. Cooper, C. H. Crouch, B. W. Dreyfus, B. D. Geller, J. Giannini, J. S. Gouvea, M. Klymkowsky, W. Losert, K. Moore, J. Presson, V. Sawtelle, K. Thompson, C. Turpen, and R. Zia, NEXUS/Physics: An interdisciplinary repurposing of physics for biologists, Am. J. Phys. 82, 368 (2014).

[19] R. A. Engle, Framing interactions to foster generative learning: A situative explanation of transfer in a Community of Learners classroom, J. Learn. Sci. 15, 451 (2006).

[20] R. A. Engle, D. P. Lam, X. E. Meyer, and S. E. Nix, How does expansive framing promote transfer? Several proposed explanations and a research agenda for investigating them, Educ. Psychol. 47, 215 (2012).

[21] J. Biggs, What the student does: Teaching for enhanced learning, Higher Educ. Res. Dev. 18, 57 (1999).

[22] S. Yerdelen-Damar and A. Elby, Sophisticated epistemologies of physics versus high-stakes tests: How do elite high school students respond to competing influences about how to learn physics?, Phys. Rev. Phys. Educ. Res. 12, 010118 (2016).

[23] A. Elby, Defining personal epistemology: A response to Hofer \& Pintrich (1997) and Sandoval (2005), J. Learn. Sci. 18, 138 (2009).

[24] W. A. Sandoval, In defense of clarity in the study of personal epistemology, J. Learn. Sci. 18, 150 (2009).

[25] T. Bing and E. F. Redish, Analyzing problem solving using math in physics: Epistemological framing via warrants, Phys. Rev. ST Phys. Educ. Res. 5, 020108 (2009).
[26] L. Lising and A. Elby, The impact of epistemology on learning: A case study from introductory physics, Am. J. Phys. 73, 372 (2005).

[27] E. Goffman, Frame Analysis: An Essay on the Organization of Experience (Harvard University Press, Cambridge, MA, 1974).

[28] D. Tannen, Framing in Discourse (Oxford University Press, New York, 1993).

[29] D. Hammer and A. Elby, On the form of a personal epistemology, Personal Epistemology: The Psychology of Beliefs about Knowledge and Knowing (L. Erlbaum Associates, Mahwah, 2002), pp. 169-190.

[30] A. Elby, C. Macrander, and D. Hammer, Epistemic cognition in science, in Handbook of Epistemic Cognition edited by J. Greene, W. Sandoval, and I. Braten (Routledge, New York, 2016), p. 113.

[31] A. Gupta and A. Elby. Beyond Epistemological Deficits: Dynamic explanations of engineering students' difficulties with mathematical sense-making, Int. J. Sci. Educ. 33, 2463 (2011).

[32] A. Elby and D. Hammer, On the substance of a sophisticated epistemology, Sci. Educ. 85, 554 (2001).

[33] J. E. Watkins, J. E. Coffey, A. C. Maskiewicz, and D. Hammer, An account of progress in teachers' epistemological framing of science inquiry, in Teachers' Personal Epistemologies: Evolving Models for Transforming Practice, edited by G. Schraw, J. L. Brownlee, L. Olafson, and M. V. V. Brye (Information Age Publishing, Charlotte, NC, 2017), pp. 87-111.

[34] S. Barzilai and A. Zohar, Reconsidering personal epistemology as metacognition: A multifaceted approach to the analysis of epistemic thinking, Educ. Psychol. 49, 13 (2014).

[35] B. Hofer, Dimensionality and disciplinary differences in personal epistemology, Contemp. Educ. Psychol. 25, 378 (2000).

[36] M. M. Buehl and P. A. Alexander, Beliefs about academic knowledge, Educ. Psychol. Rev. 13, 385 (2001).

[37] C. Tsai, Biological Knowledge is more tentative than physics knowledge: Taiwan high school adolescents' views about the nature of biology and physics, Adolescence 41, 691 (2006).

[38] K. B. Lucas and W.-M. Roth, The nature of scientific knowledge and student learning: Two longitudinal case studies, Res. Sci. Educ. 26, 103 (1996).

[39] K. Hogan, Exploring a process view of students' knowledge about the nature of science, Sci. Educ. 84, 51 (2000).

[40] W. A. Sandoval, Understanding students' practical epistemologies and their influence on learning through inquiry, Sci. Educ. 89, 634 (2005).

[41] J. S. Gouvea, V. Sawtelle, B. D. Geller, and C. Turpen, A framework for analyzing interdisciplinary tasks: Implications for student learning and curricular design, CBE Life Sci. Educ. 12, 187 (2013).

[42] B. A. Danielak, A. Gupta, and A. Elby, Marginalized identities of sense-makers: Reframing engineering student retention, J. Eng. Educ. 103, 8 (2014).

[43] D. L. Schwartz, J. D. Bransford, and D. Sears, Efficiency and innovation in transfer, in Transfer of Learning from a Modern Multidisciplinary Perspective, edited by 
J. Mestre (Information Age Publishing, Charlotte, NC, 2005), pp. 1-51.

[44] D. Hemmingway, V. Sawtelle, and C. Turpen. How an educator characterizes scientific domains and disciplinary relationships: A case of change, in PERC Proceedings (AIP Press, Melville, NY, 2015).

[45] K. L. Hall, Examining the effects of students' classroom expectations on undergraduate biology course reform, Ph.D. thesis, University of Maryland, 2013.

[46] J. L. Momsen, T. A. Long, and S. A. Wyse, Just the facts? Introductory undergraduate biology courses focus on lowlevel cognitive skills, CBE Life Sci. Educ. 9, 435 (2010).

[47] E. F. Redish and T. J. Cooke, Learning each other's ropes: Negotiating interdisciplinary authenticity, CBE Life Sci. Educ. 12, 175 (2013).

[48] J. E. Watkins, K. L. Hall, J. E. Coffey, T. J. Cooke, and E. F. Redish, Disciplinary authenticity: Enriching the reform of introductory physics courses for life science students, Phys. Rev. ST Phys. Educ. Res. 8, 010112 (2012).

[49] C. H. Crouch and K. Heller, Introductory physics in biological context: An approach to improve introductory physics for life science students, Am. J. Phys. 82, 378 (2014).
[50] D. C. Meredith and J. A. Bolker, Rounding off the cow: Challenges and successes in an interdisciplinary physics course for life science students, Am. J. Phys. 80, 913 (2012).

[51] B. W. Dreyfus, V. Sawtelle, C. Turpen, J. Gouvea, and E. F. Redish, Students' reasoning about "high-energy bonds" and ATP: A vision of interdisciplinary education, Phys. Rev. ST Phys. Educ. Res. 10, 010115 (2014).

[52] V. Sawtelle and C. Turpen, Leveraging a relationship with biology to expand a relationship with physics, Phys. Rev. Phys. Educ. Res. 12, 010136 (2016).

[53] J. Svoboda and C. Passmore, The strategies of modeling in biology education, Sci. Educ. 22, 119 (2013).

[54] S. D. Hester, M. Nadler, J. Katcher, L. K. Elfring, E. Dykstra, L. Rezende, and M. S. Bolger, Authentic inquiry through modeling in biology (aim-bio): An introductory laboratory curriculum that increases undergraduates' scientific agency and skills, CBE Life Sci. Educ. 17, ar63 (2018).

[55] C. Henderson, M. Connolly, E. L. Dolan, N. Finkelstein, S. Franklin, S. Malcom, and S. K. St. John, Towards the STEM DBER Alliance: Why we need a discipline-based STEM education research community. Int. J. STEM Educ. 4, 14 (2017). 